\title{
A Critical Reanalysis of Uncontrollable Washboarding Phenomenon in Metal Band Sawing
}

\author{
Kazimierz A. Orlowski ${ }^{1}{ }^{\circledR}$, Michal Dobrzynski ${ }^{1} \oplus$, Grzegorz Gajowiec ${ }^{2}$, Marcin Lackowski ${ }^{3}$ \\ and Tomasz Ochrymiuk ${ }^{3, *(\mathbb{D})}$ \\ 1 Department of Manufacturing and Production Engineering, Faculty of Mechanical Engineering, \\ Gdansk University of Technology, Gabriela Narutowicza 11/12, 80-233 Gdańsk, Poland; \\ kazimierz.orlowski@pg.edu.pl (K.A.O.); michal.dobrzynski@pg.edu.pl (M.D.) \\ 2 Department of Materials Engineering and Bonding, Faculty of Mechanical Engineering, Gdansk University \\ of Technology, Gabriela Narutowicza 11/12, 80-233 Gdańsk, Poland; grzgajow@pg.edu.pl \\ 3 Institute of Fluid-Flow Machinery Polish Academy of Sciences, 80-233 Gdańsk, Poland; mala@imp.gda.pl \\ * Correspondence: tomasz.ochrymiuk@imp.gda.pl; Tel.: +48-58-5225-171
}

Received: 19 August 2020; Accepted: 6 October 2020; Published: 9 October 2020

check for updates

\begin{abstract}
The article analyzes the cutting process of hard bars. Investigations conducted in industrial conditions demonstrated the presence of surface errors in the machined workpieces in the form of washboard patterns. The purpose of this study was to analyze the results of cutting on band sawing machines with different band saw blades. The cutting processes were conducted on three different horizontal band sawing machine types. Analyzed material was an alloy steel $\varnothing 40 \mathrm{~mm}$ rod with a hardened surface covered with a thin layer of chromium. The hardness of the outer layer was $547 \mathrm{HV}$ with a core hardness of $180 \mathrm{HV}$. The surface topography measurements of the processed workpieces were carried out with the 3D Optical Profiler, which supplied information on the irregularities of the processed material texture. In each of the analyzed cases, a corrugated surface was obtained after sawing, which is the effect of the occurrence of the washboarding phenomenon, despite the fact that the teeth of each band saw had variable pitches. The washboarding phenomenon when cutting rods with hard surfaces is caused by the phenomenon of wave regeneration. Despite the use of variable pitch saw blades, the cutting process results in rippling of the sawn surface, which is caused by the high hardness of the outer layer of the workpiece, as well as by the type of tool with spring setting of teeth.
\end{abstract}

Keywords: metal band sawing; washboarding phenomenon; empirical test; 3D cut surface examination; waviness profiles analyses

\section{Introduction}

Round materials and profiles can be cut on circular, frame, and band sawing machines. The latter group is widely used because of the possibility of process automation, small kerf losses, straightness of the kerf, good surface quality, as well as long saw blade life [1]. Cutting with band saw blades is characterized by the fact that the thicknesses of the cut layers are small, the nature of the cutting edges work is intermittent [2], the number of cutting edges in contact with the workpiece can change, and the saw blade itself is an object of low own stiffness [3,4].

Although in many cases cutting of rods is done on CNC-controlled band saws, the cutting performance is worse than that achieved by modern circular saws. Due to the quality of the surface obtained after the band sawing operation, at least two turning operations are always required when machining the face surfaces. The first treatment is a coarse treatment for the initial achievement of the required dimension and leveling of potential irregularities (perpendicularity error), and the 
next is the finishing operation for obtaining the final dimension and the required surface roughness. Conversely, after cutting on a circular sawing machine, the initial turning operation is omitted and only the finishing operation is performed [5].

As a result of the fact that cutting is the first technological operation, the effects of which are often removed during subsequent operations, there are not many scientific works in this area. A common case of errors when cutting with band saws is the occurrence of a characteristic wave on the cut surface. In recent years, a number of papers analyzed the problems of loss of stability in the cutting process of band saws where the authors

- Used signals of sound pressure, vibrations and cutting forces for the proprietary method of detecting chatter vibrations, which in this case were independent of the workpiece geometry and cutting parameters [6,7];

- Developed a model in which the free length of the saw blade, cutting speed, and feed speed were taken into account to determine stability regions, which avoid the presence of chatter vibrations when cutting [8]. Two strategies have been proposed to avoid this type of phenomenon, the first of which is to reduce and the second to increase the cutting speed to find working parameters outside the area where there would be a risk of loss of stability $[8,9]$.

It should be emphasized that chatter vibrations are the result of a number of phenomena during the cutting process occurring in the cutting zone on the main cutting edge $[10,11]$. On the other hand, when cutting with saws, three cutting edges are involved in cutting, for the simplest geometry, the main edge, and two minor cutting edges (Figure 1). The position of the minor cutting edges $S^{\prime}$ is defined by the minor tool cutting edge angles $\kappa_{r}^{\prime}$ (Figure $\left.1 b\right)$.

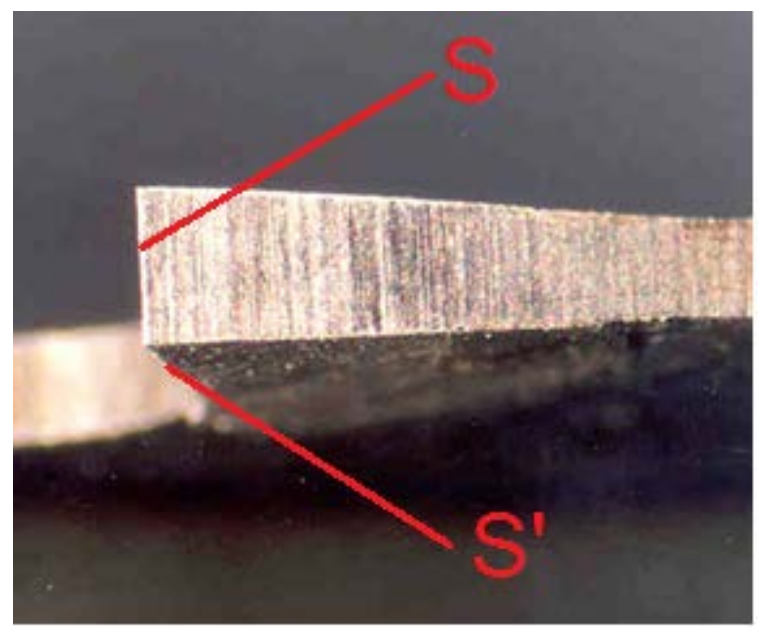

(a)

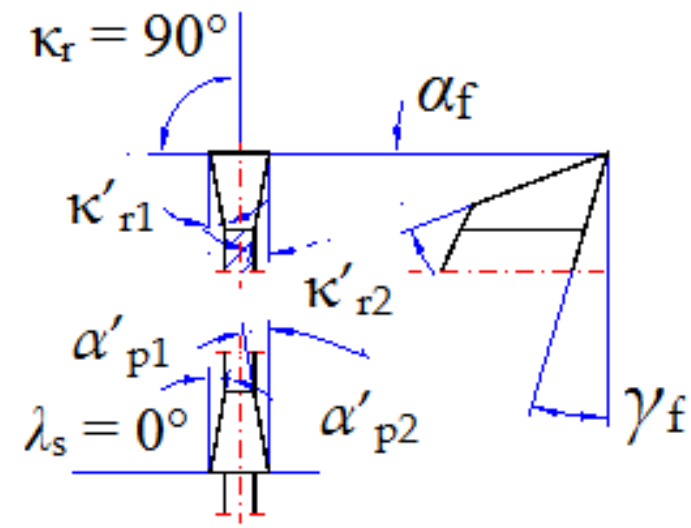

(b)

Figure 1. Band saw tooth general view from the top (a) and its geometry in the tool-in-hand system (b), where S-main cutting edge, $\mathrm{S}^{\prime}-$ minor cutting edge, $\alpha_{\mathrm{f}}$ the tool side flank, $\alpha_{\mathrm{p}}^{\prime}$ the tool back flank, $\mathrm{K}_{\mathrm{r}}$ tool cutting edge angle, $\kappa_{r}^{\prime}$ minor tool cutting edge angle, $\gamma_{\mathrm{f}}$ the tool side rake, and $\lambda_{\mathrm{s}}$ the cutting edge inclination angle.

Phenomena occurring on the minor cutting edges, caused by back forces (perpendicular to the saw blade) are responsible for the formation of waviness of the cut surface [12,13]. Hereafter, to distinguish from chatter vibrations, the phenomenon of surface rippling when cutting with saws due to loss of stability will be called the washboarding, as it was done by Okai [14] and Orlowski and Wasielewski [15]. Ni et al. [3] developed and experimentally verified the dynamic model of cutting forces when cutting on band saws. The problems of wear of teeth of saw blades while cutting bearing steel were described by Sarwar et al. [1]. Boland et al. [16] provided an overview of the developments in diamond composite materials with particular emphasis on microstructural characterization. Those investigations greatly 
help in the design of innovative diamond tools for cutting, drilling, and sawing processes. The 3D topography measurements allow one to perform a comprehensive quantitative evaluation of a surface after cutting. The evaluation of surface texture formed during turning of $\mathrm{CoCr}$ alloys fabricated by casting and SLM processes was presented by Krawczyk et al. [17]. The influence of cutting parameters (speed, feed rate, and depth) during dry turning on the areal surface roughness of AZ31B Magnesium Alloy was thoroughly investigated by Gao et al. [18].

When cutting hard bars on band sawing machines in industrial conditions, geometric errors generated in the sawn surfaces by cutting take the form of washboard patterns. The present study aims to analyze in-depth the results of cutting operations on band sawing machines with different band saw blades.

\section{Materials and Methods}

\subsection{Materials}

In the analyzed cases, the cut material was a rod with a diameter of $\varnothing 40 \mathrm{~mm}$ from alloy steel (grade of steel 66Mn4 (1.1260)) with a hardened surface. Moreover, its surface was covered with a thin layer of chromium. The hardness of the outer layer was $547 \mathrm{HV}$ (about $52 \mathrm{HRC}$ ), while core hardness was $180 \mathrm{HV}$. HV hardness was determined on the Vickers-Brinell hardness tester HPO 250 (Hegewald \& Peschke Meß- und Prüftechnik GmbH, Nossen Germany). The structure of the hardened layer $(547 \mathrm{HV}$ ) of the workpiece (with a thickness of about $2 \mathrm{~mm}$ ) was mainly made by martensite with a small amount of ferrite, as shown in Figure 2a. On the other hand, Figure $2 b$ shows the structure of the rod core $(180 \mathrm{HV})$, in which pearlite and ferrite are observed.

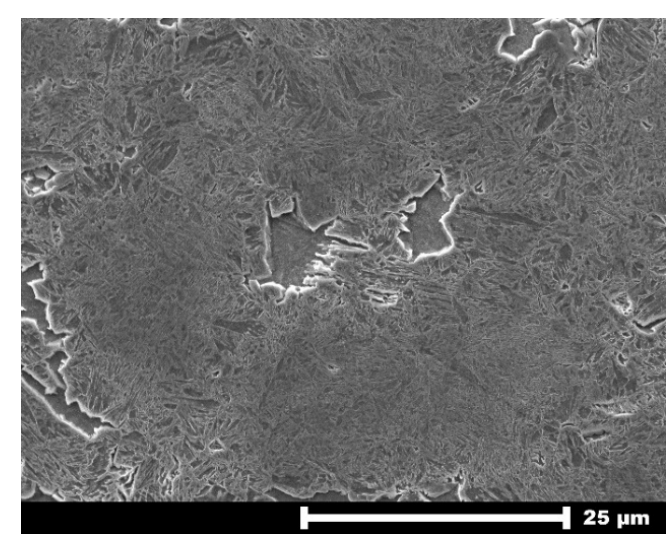

(a)

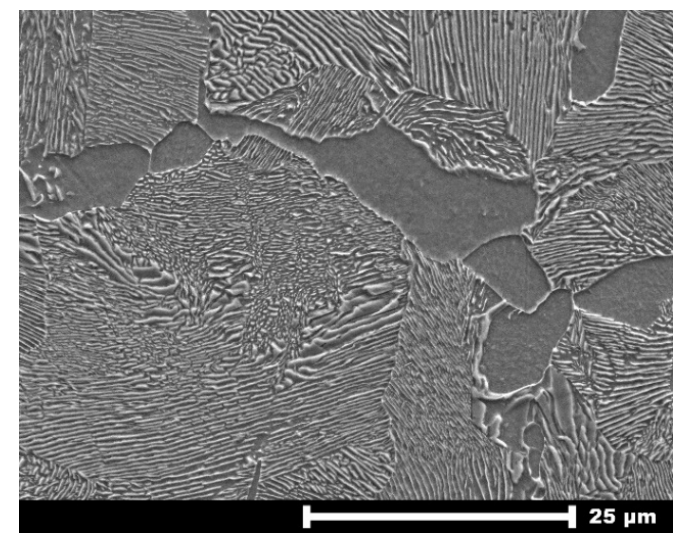

(b)

Figure 2. Rod metallographic structures: martensitic-ferritic outer layer (a) and pearlitic-ferritic core (b), obtained by SEM electron microscope (magnification 2000×). 


\subsection{Types of Cutting Machines and Tools}

The cutting process case \#1 was conducted on the horizontal band sawing machine type JB250 (unknown producer) with a tool of technical data: bimetal bandsaw, back to tip tooth height $\mathrm{B}=27 \mathrm{~mm}$, blade thickness s $=0.9 \mathrm{~mm}$, variable pitch $(\mathrm{P}) 4 / 6$ teeth per inch (TPI), teeth set pattern: straight-right-left sequence; tooth tip material: high speed steel M71-C (1000 HV, according to American Iron and Steel Institute (AISI)). Cutting parameters: cutting speed $\mathrm{v}_{\mathrm{c}}=34 \mathrm{~m} \cdot \mathrm{min}^{-1}$ and feed speed $6.7 \mathrm{~mm} \cdot \mathrm{min}^{-1}$ (feed per tooth $\mathrm{f}_{\mathrm{z}} \approx 1 \mu \mathrm{m}$ ).

In the case \#2, the cutting process was carried out on the horizontal band sawing machine type HBP220A (producer Behringer, D, Kirchardt, Germany) with a tool of technical data: bimetal bandsaw, back to tip tooth height $\mathrm{B}=34 \mathrm{~mm}$, blade thickness $\mathrm{s}=1.1 \mathrm{~mm}$, variable pitch $(\mathrm{P}) 3 / 4 \mathrm{TPI}$, teeth set pattern: straight-right-left sequence; tooth tip material high: speed steel M42 (950 HV, according to AISI). Cutting parameters: cutting speed $\mathrm{v}_{\mathrm{c}}=27 \mathrm{~m} \cdot \mathrm{min}^{-1}$ and feed speed $1.1 \mathrm{~mm} \cdot \mathrm{min}^{-1}$ (feed per tooth $\mathrm{f}_{\mathrm{z}} \approx 0.3 \mu \mathrm{m}$ ).

In the case \#3, the cutting process was realized on the horizontal band sawing machine type HBP413A (producer Behringer, D) with a tool of technical data: bimetal bandsaw, back to tip tooth height $\mathrm{B}=41 \mathrm{~mm}$, blade thickness $\mathrm{s}=1.3 \mathrm{~mm}$, variable pitch (P) 2/3 TPI, teeth set pattern: straight-right-left sequence; tooth tip material high: speed steel M42 (950 HV, according to AISI). Cutting parameters were cutting speed $\mathrm{v}_{\mathrm{C}}=23 \mathrm{~m} \cdot \mathrm{min}^{-1}$ and feed speed $3 \mathrm{~mm} \cdot \mathrm{min}^{-1}$ (feed per tooth $\mathrm{f}_{\mathrm{z}} \approx 1.3 \mu \mathrm{m}$ ).

It ought to be emphasized that cutting parameters were taken from Perschmann handbook [19] and suggested by the experienced engineers from the plant, where tests were conducted.

Basic technical data of bandsaws used in experiments are presented in Table 1.

Table 1. Basic technical data of bandsaws.

\begin{tabular}{ccccc}
\hline Case & $\begin{array}{c}\text { B } \\
{[\mathbf{m m}]}\end{array}$ & $\begin{array}{c}\text { s } \\
{[\mathbf{m m}]}\end{array}$ & $\begin{array}{c}\text { P } \\
{[\text { TPI] }}\end{array}$ & Set Pattern \\
\hline$\# 1$ & 27 & 0.9 & $4 / 6$ & straight-right-center \\
$\# 2$ & 34 & 1.1 & $3 / 4$ & straight-right-center \\
$\# 3$ & 41 & 1.3 & $2 / 3$ & straight-right-center
\end{tabular}

Legend: TPI—number of teeth per inch; pattern: repeatable teeth grouping; straight-teeth not bent, right—-eeth bent in the right side, left-teeth bent in the left side.

\subsection{Cut Surface Examination}

The surface topography measurements of the processed workpieces were carried out with the 3D Optical Profiler S neox (Sensofar 2019, Sensofar Metrology, Terrassa, Spain) [20] with objective 5× EPI of Nikon. The system was controlled by SensoSCAN 6.6 software (v.6.6, Sensofar Metrology, Terrassa, Spain), and the basic details of the measurement were set as follows:

- $\quad$ Topography: $8759 \times 8770$ px (Sample K\#1), 16,377 × 16,662 px (Sample K\#2) and $7846 \times 8332$ px (Sample K\#3);

- $\quad$ Pixel size: $5.2 \mu \mathrm{m} /$ pixel for Sample K\#1 and K\#3, 2.6 m/pixel for Sample K\#2;

- $\quad$ Axis Z-Scan step of $12 \mu \mathrm{m}$;

- Threshold 3\%;

- Algorithm: Confocal Fusion.

Surface analyses were conducted with MountainsMap 7.1 software package (2019, Digital Surf made available Optotom,) Warsaw, Poland, Besançon, France. In order to analyze texture, the general slope of a sample was removed using a levelling process. Therefore, the "Level" Operator was applied, in accordance with ISO 25178 [21], based on the least-squares form fitting levelling, using an LS-plane. Additionally, the median-type spatial filtering of $3 \times 3$ and $9 \times 9$ size for measured samples were used. The purpose of these filters was to reduce the noise in an image and the microroughness on analyzed surfaces. 
On the S-F surfaces (surface derived from the primary surface by removing the form, in accordance with ISO 25178-2 [22]) three control paths lying on parallel lines with a constant spacing of $25 \%$ of the ROI size were defined for extracting W-profiles from the S-F surfaces (Figure 3).
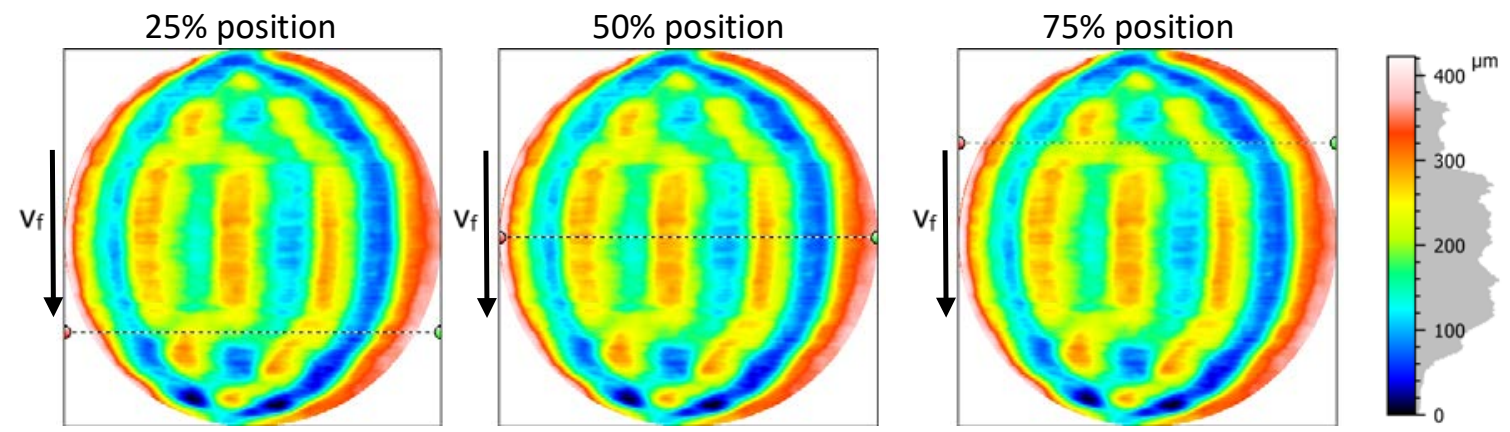

Figure 3. Positions of the control paths defined for sample K\#3 for extracting W-profiles based on waviness surfaces, where arrow $v_{\mathrm{f}}$ is a direction feeding, and $\mathrm{v}_{\mathrm{f}}$ is feed speed.

\section{Results and Discussion}

In each of the analyzed cases, a corrugated surface was obtained after sawing (Figure 4), which is the effect of the occurrence of the washboarding phenomenon, despite the fact that the teeth of each band saw had variable pitches (\#1-4/6 TPI, \#2-3/4 TPI and \#3-2/3 TPI), which should prevent instability in the machining process according to the theory [11].

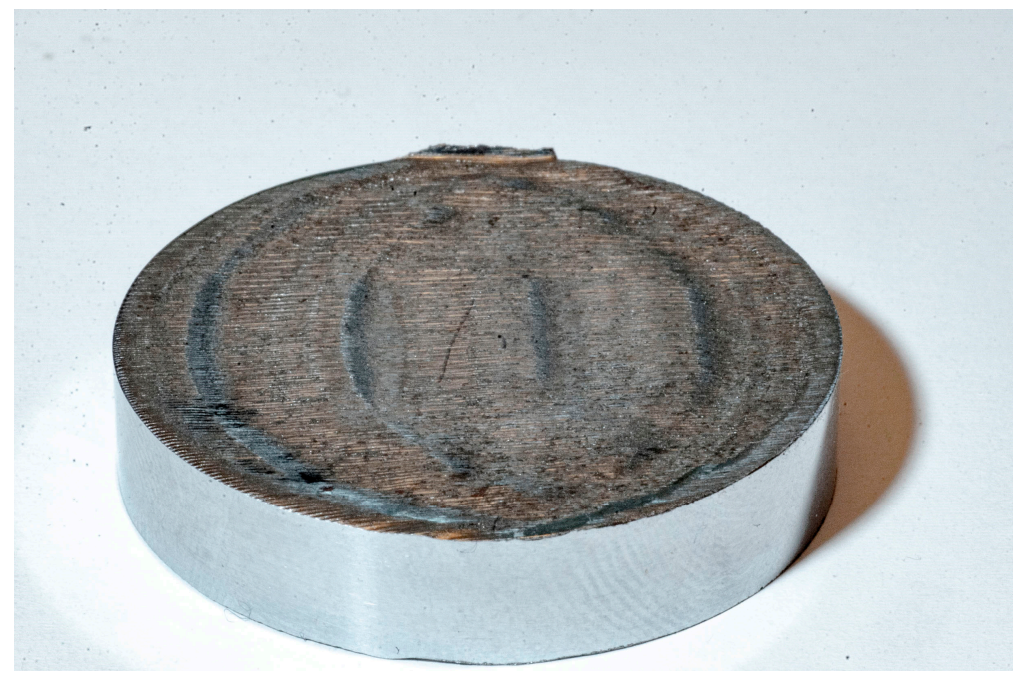

Figure 4. General view of the sample \#1 with the washboard pattern on the sawn surface.

Kimura et al. [12] have shown that under certain conditions, the use of variable pitches of a band saw teeth does not produce the desired results. Moreover, changes of impact frequencies on the sash gang saw were in the range 0 to several hundred $\mathrm{Hz}$ in one cycle; saw blades with spring setting of teeth, which had minor-cutting-edge feathers after grinding, did not prevent this type of waviness (presence of washboarding pattern) [15].

In Figure 5, exemplary 3D waviness surfaces of the samples \#1, \#2 and \#3 are presented. All S-F surfaces of samples were obtained by applying a Gaussian filter, in accordance with ISO 16610-61 [23]. The choice of the nesting index (cut-off) of $0.8 \mathrm{~mm}$ was connected with obtaining a surface texture with visible reliefs of the workpiece surface after sawing. 


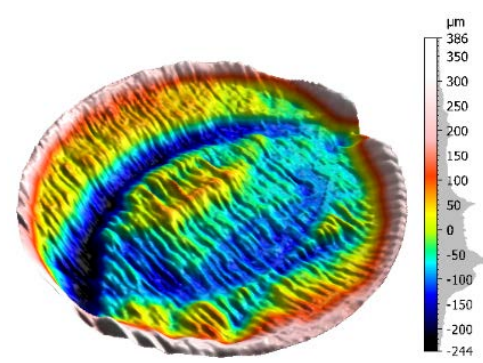

(a)

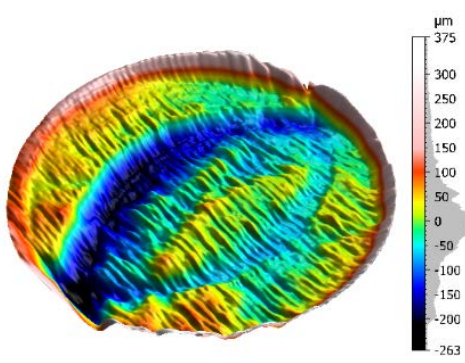

(b)

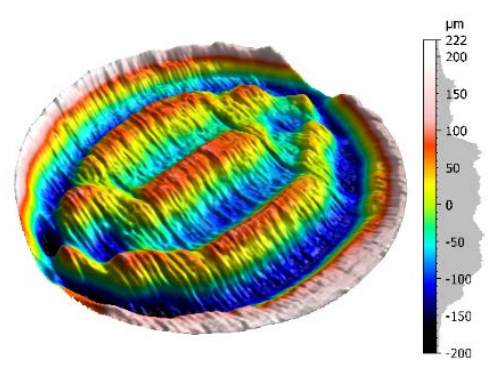

(c)

Figure 5. 3D waviness surface under investigation of the samples \#1 (a), \#2(b), and \#3 (c).

The main height parameters of the S-F sample surfaces: Sq-root mean square roughness, $\mathrm{Sp}$-maximum peak height, Sv-maximum valley depth, and Sz-maximum height of the surface, in accordance with ISO 25178 [24], are presented in Table 2.

Table 2. Main height parameters of the S-F examined sample surfaces.

\begin{tabular}{cccc}
\hline $\boldsymbol{-}$ & \#1 & \#2 & \#3 \\
\hline Sq $[\mu \mathrm{m}]$ & 109.97 & 96.62 & 80.29 \\
$\mathrm{Sp}[\mu \mathrm{m}]$ & 386.34 & 375.35 & 222.10 \\
$\mathrm{~Sv}[\mu \mathrm{m}]$ & 244.25 & 263.39 & 200.32 \\
$\mathrm{Sz}[\mu \mathrm{m}]$ & 631.59 & 638.73 & 422.42 \\
\hline
\end{tabular}

The height parameters of the S-F surfaces (Table 1) point out that the maximum height between the edge of the sample and the maximum depth of the furrows is much larger for samples \#1 and \#2. In the case of sample \#3, such value reaches $422 \mu \mathrm{m}$, and it is $200 \mu \mathrm{m}$ smaller than for other samples. $\mathrm{Sp}$ and Sv parameters of the sample \#3 indicate regular spacing of hills and valleys.

Further study supplied information about the maximum and the mean depth of the furrows (Figure 6).

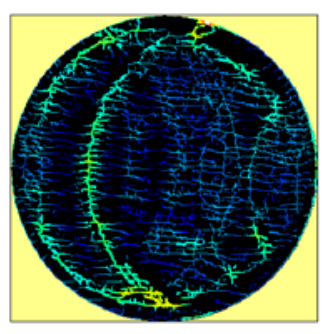

(a)

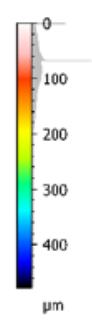
(a)

Figure 6. View of the furrows of the samples \#1 (a), \#2 (b), and \#3 (c).

Data on furrow depth and density gathered from the examined surfaces are presented in Table 3. The obtained mean values oscillated around $100 \mu \mathrm{m}$, the maximum depth of samples of furrows for sample \#3 was about $200 \mu \mathrm{m}$ lower than for sample \#1. In all cases, the density of the furrows, defined as a cumulative length per area unit (in $1 / \mathrm{cm}$ ), were at the similar level.

Table 3. Parameters of furrows contained in examined sawn samples.

\begin{tabular}{cccc}
\hline & \#1 & \#2 & \#3 \\
\hline Max. depth of furrows $[\mu \mathrm{m}]$ & 474.40 & 314.80 & 290.86 \\
Mean depth of furrows $[\mu \mathrm{m}]$ & 103.13 & 107.27 & 98.05 \\
Mean density of furrows $[1 / \mathrm{cm}]$ & 13.92 & 13.38 & 13.01 \\
\hline
\end{tabular}


Table 3 lists the waviness parameters extracted from the W-profiles corresponding to the three parallel control paths defined for each specimen; the cut-off value of profiles (set as $0.8 \mathrm{~mm}$ (ISO 4287 [24])) was collected in Table 4. Parameters in Table 4 are as follows: Wp-waviness maximum profile peak height, $\mathrm{Wv}$-waviness maximum profile valley depth, $\mathrm{Wz}$-maximum height of the waviness profile, and $\mathrm{Wq}$ - waviness root mean square deviation.

Table 4. Waviness parameters of the profiles extracted in selected positions of samples.

\begin{tabular}{cccccccccc}
\hline & \multicolumn{3}{c}{$\# \mathbf{1}$} & \multicolumn{3}{c}{$\# \mathbf{2}$} & \multicolumn{3}{c}{ Position } \\
\cline { 2 - 10 } & \multicolumn{3}{c}{ Position } & \multicolumn{3}{c}{ Position } & \multicolumn{3}{c}{ P } \\
\cline { 2 - 10 } & $\mathbf{2 5 \%}$ & $\mathbf{5 0 \%}$ & $\mathbf{7 5 \%}$ & $\mathbf{2 5 \%}$ & $\mathbf{5 0 \%}$ & $\mathbf{7 5 \%}$ & $\mathbf{2 5 \%}$ & $\mathbf{5 0 \%}$ & $\mathbf{7 5 \%}$ \\
\hline Wp $[\mu \mathrm{m}]$ & 267.83 & 247.81 & 250.39 & 359.34 & 260.33 & 262.72 & 183.97 & 204.75 & 160.60 \\
Wv $[\mu \mathrm{m}]$ & 185.38 & 182.00 & 127.49 & 166.92 & 181.10 & 142.38 & 134.36 & 137.18 & 117.21 \\
Wz $[\mu \mathrm{m}]$ & 453.21 & 429.81 & 377.88 & 526.26 & 441.43 & 405.10 & 318.33 & 341.93 & 277.81 \\
Wq $[\mu \mathrm{m}]$ & 119.32 & 93.15 & 91.50 & 97.08 & 82.11 & 76.60 & 75.04 & 77.10 & 63.56 \\
\hline
\end{tabular}

An exemplary $\mathrm{W}$-profile at $50 \%$ position of the sample \#3 is presented in Figure 7 . According to the values of waviness parameters and profile information given in Table 3 , the middle of the machined samples \#1 and \#2 was distinctly above the edge, 2-3 $\mu \mathrm{m}$ wide, and with deep furrows. In sample \#3, all of the furrows after machining process were well visible and their height was similar level to regular spacing of hills and valleys.

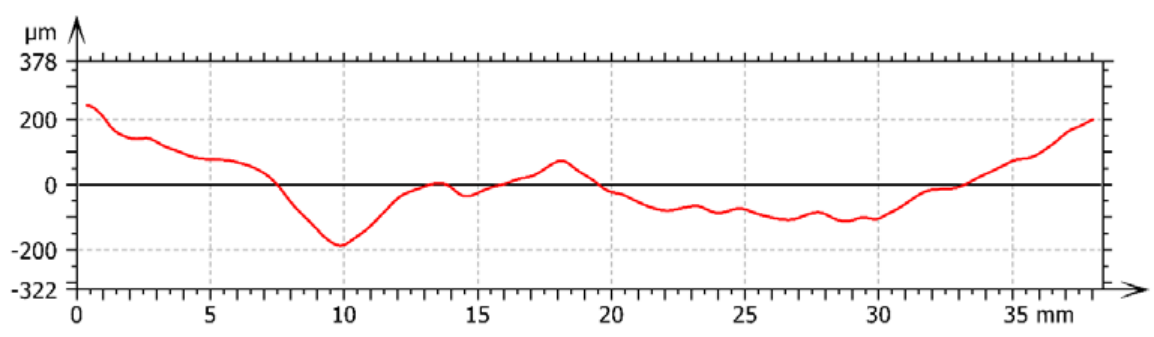

(a)

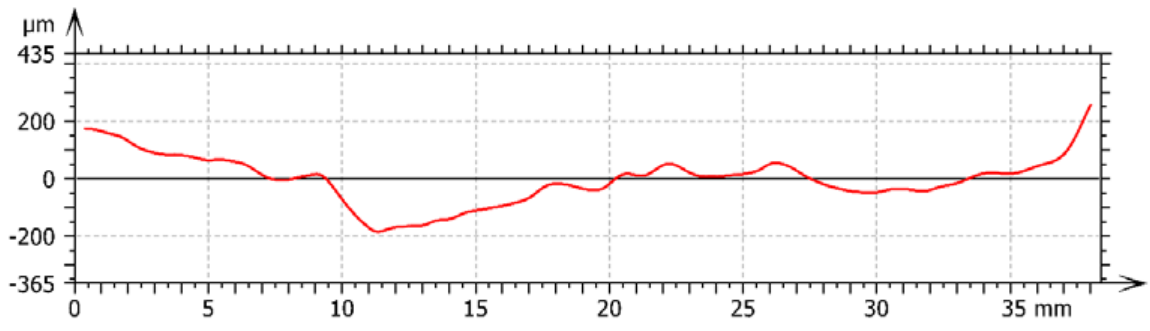

(b)

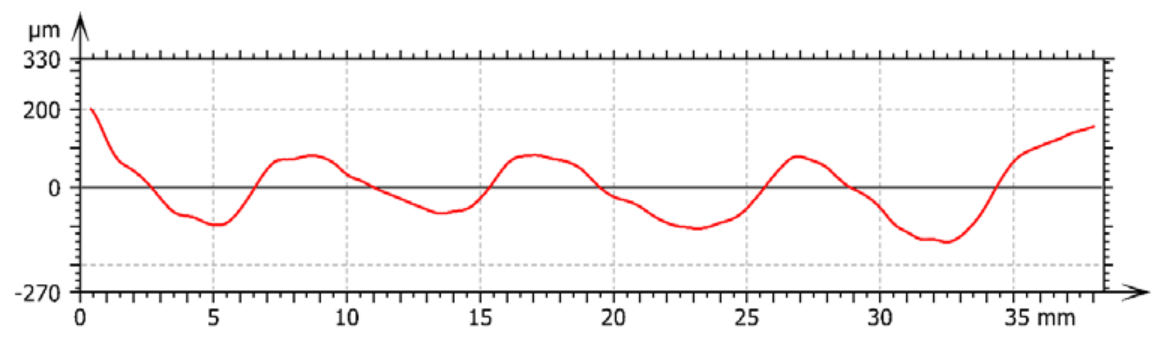

(c)

Figure 7. Exemplary W-profile at 50\% position of the samples \#1 (a), \#2 (b), and \#3 (c). 
The use of variable teeth pitches of teeth in all experiments did not result in machined surfaces without waviness errors. The average values of the excitation frequencies were for the cases $\# 1 \mathrm{f}_{a}=110 \mathrm{~Hz}$, $\# 2 \mathrm{f}_{\mathrm{a}}=62 \mathrm{~Hz}$, and \#3 $\mathrm{f}_{\mathrm{a}}=37.7 \mathrm{~Hz}$, respectively.

The phenomenon of the occurrence of the corrugated surfaces after sawing in this case could be due to the behavior of the saw blade with spring setting teeth caused by the high hardness of the outer layer of the sawn rod $(547 \mathrm{HV})$. For spring setting teeth, the saw blade during entrance into cut material is twisted by the lateral forces (back forces). Under specific cutting conditions, while the washboard pattern is formed, every successive cutting edge regenerates a wave performed by the previous one. Nevertheless, this new wave is part of a distance velocity lag in the direction of primary motion. The result of this wave regeneration on the sawn surface is visible as a washboard pattern, which can be described by parameters of waviness. The wave regeneration in the examined cases is not a time function but a function of the saw blade position and simultaneous effect of forced excitations of the formed wave upon the saw blade lateral displacements. This phenomenon was described in detail by Orlowski and Wasielewski [15], who analyzed process of sawing beech and pine wood on the sash gang saw PRW15-M. In the sawing process, they used saw blades of poor quality of teeth cutting edges after grinding (minor cutting edges with feathers). It should be emphasized that waviness parameters for those species were almost equal.

In the described cases we are dealing with, the opposite phenomenon-the role of the object forcing the behavior of the saw blade-is played by the hard outer layer of the workpiece, not by the poor quality of the tool blade.

\section{Conclusions}

Despite the use of variable pitch saw blades in the process of cutting on different band saws, there may be a washboarding phenomenon, resulting in rippling of the sawn surface, which is caused by the high hardness of the outer layer of the workpiece, as well as by the type of tool with spring setting of teeth.

The conducted surface topography measurements of the processed workpieces, which were carried out with the 3D Optical Profiler S neox, revealed that waviness height parameters were at a similar level. Nevertheless, the small reduction in Wz maximum height of the waviness profile is observed with an increase of teeth pitches.

As when shaping the washboard pattern while sawing wood with poor quality of teeth cutting edges, the washbording phenomenon when cutting rods with hard surfaces with bandsaws, which have spring setting teeth, is caused by the phenomenon of wave regeneration.

Based on the study, the performed application of bandsaws with spring setting teeth is strongly discouraged for cutting-off hard-to-machine materials. If this type of bandsaw is used, in the next step another technological operation, e.g., turning, is needed. On the other hand, with such a difficult technological task, cutting-off wire electro discharging machining (WEDM) could be recommended.

Author Contributions: Conceptualization, K.A.O., M.D., M.L., and T.O.; formal analysis, K.A.O., M.D., and G.G.; investigation, K.A.O., M.D., and G.G.; methodology, K.A.O., M.D., and T.O.; writing-original draft, K.A.O., M.D., and G.G.; writing-review and editing, K.A.O., M.D., M.L., and T.O. All authors have read and agreed to the published version of the manuscript.

Funding: This research received no external funding.

Acknowledgments: The authors wish to thank Andrzej Szczypek CEO of the SIM Gdynia for providing band sawing machines and tools used in the experiments. The authors would like to acknowledge the firm Optotom (Warsaw, Poland) for 3D surface texture measurements with the 3D Optical Profiler S Neox. The authors wish to thank the firm Sword Sp. z o.o., s. k. for providing steel rods and tools used in the study. The role of Eng. Lech Targan, ought to be acknowledged for his inspiration, thanks to which the authors dealt with the issues described in this study.

Conflicts of Interest: The authors declare no conflict of interest. 


\section{References}

1. Sarwar, M.; Persson, M.; Hellbergh, H. Wear and failure modes in the bandsawing operation when cutting ball-bearing steel. Wear 2005, 259, 1144-1150. [CrossRef]

2. Alspaugh, D.W. Torsional vibration of a moving band. J. Frankl. Inst. 1967, 283, 328-338. [CrossRef]

3. Ni, J.; Li, L.; Al-Furjan, M.S.H.; Xu, J.; Yang, X. Establishment and verification of a dynamic cutting force model for metal bandsawing. Int. J. Adv. Manuf. Technol. 2017, 90, 2703-2712. [CrossRef]

4. Thaler, T.; Bric, I.; Bric, R.; Potočnik, P.; Muzic, P.; Govekar, E. Characterization of band sawing based on cutting forces. J. Mach. Eng. 2012, 12, 41-54.

5. Szczypek, A.; Orlowski, K. Analiza produktywności procesów przecinania materiałów prętowych. In Obróbka skrawaniem zaawansowana technika; Latoś, H., Ed.; Wydawnictwo Uczelniane Uniwersytetu Technologiczno-Przyrodniczego: Bydgoszcz, Poland, 2009; pp. 367-374.

6. Potočnik, P.; Thaler, T.; Govekar, E. Multisensory chatter detection in band sawing. Procedia CIRP 2013, 8, 469-474. [CrossRef]

7. Thaler, T.; Potočnik, P.; Bric, I.; Govekar, E. Chatter detection in band sawing based on discriminant analysis of sound features. Appl. Acoust. 2014, 77, 114-121. [CrossRef]

8. Thaler, T.; Krese, B.; Govekar, E. Stability diagrams and chatter avoidance in horizontal band sawing. CIRP Ann. Manuf. Technol. 2015, 64, 81-84. [CrossRef]

9. Thaler, T.; Potočnik, P.; Kopač, J.; Govekar, E. Experimental chatter characterization in metal band sawing. Stroj. Vestn. J. Mech. Eng. 2014, 60, 265-273. [CrossRef]

10. Kalinski, K.J.; Galewski, M.A. Optimal spindle speed determination for vibration reduction during ball-end milling of flexible details. Int. J. Mach. Tools Manuf. 2015, 92, 19-30. [CrossRef]

11. Tomków, J. Wibrostabilność obrabiarek. Komputerowe wspomaganie obliczeń i badań doświadczalnych; (In Polish: Machine Tools Vibro-Stability. Computer-Aided Calculations and Experiments); WNT: Warszawa, Poland, 1997.

12. Kimura, S.; Yokochi, H.; Edamura, M.; Kojima, Y. Remodeled bandsaw to control washboarding during sawing II. In Proceedings of the 15th International Wood Machining Seminar, Los Angeles, CA, USA, 30 July-1 August, 2001; pp. 199-204.

13. Lehmann, B.F. The Cutting Behavior of Bandsaws. Ph.D. Thesis, Department of Mechanical Engineering, The University of British Columbia, Vancouver, Canada, 1993. Available online: https://open.library.ubc.ca/ cIRcle/collections/ubctheses/831/items/1.0080916 (accessed on 25 April 2020).

14. Okai, R. Influence of vibration coupling between bandsaw frame and feed-carriage system on sawdust spillage and surface quality of workpiece during sawing. Eur. J. Wood Wood Prod. 2009, 67, 189-195. [CrossRef]

15. Orlowski, K.; Wasielewski, R. Study washboarding phenomenon in frame sawing machines. Holz als Rohund Werkstoff 2006, 64, 37-44. [CrossRef]

16. Boland, J.N.; Li, X.S. Microstructural characterisation and wear behaviour of diamond composite materials. Materials 2010, 3, 1390-1419. [CrossRef]

17. Krawczyk, M.; Królikowski, M.; Grochała, D.; Powałka, B.; Figiel, P.; Wojciechowski, S. evaluation of surface topography after face turning of $\mathrm{CoCr}$ alloys fabricated by casting and selective laser melting. Materials 2020, 13, 2448. [CrossRef] [PubMed]

18. Gao, H.; Ma, B.; Singh, R.; Yang, H. Areal surface roughness of AZ31B magnesium alloy processed by dry face turning: An experimental framework combined with regression analysis. Materials 2020, 13, 2303. [CrossRef] [PubMed]

19. Perschmann—Hoffmann Group. Machining handbook—cutting data part. Available online: https://ecatalog. hoffmann-group.com/index.html (accessed on 23 September 2020).

20. Sensofar. 2017. Available online: http://www.sensofar.com/metrology/sneox/ (accessed on 22 April 2020).

21. ISO 25178-607:2019. Geometrical Product Specifications (GPS)—Surface Texture: Areal—Part 607: Nominal Characteristics of Non-Contact (Confocal Microscopy) Instruments; International Organization for Standardization: Geneva, Switzerland, 2019.

22. ISO 25178-2:2012. Geometrical Product Specifications (GPS)—Surface Texture: Areal_Part 2: Terms, Definitions and Surface Texture Parameters; International Organization for Standardization: Geneva, Switzerland, 2012. 
23. ISO 16610-61:2015. Geometrical Product Specification (GPS)_Filtration_Part 61: Linear areal Filters—Gaussian Filters; International Organization for Standardization: Geneva, Switzerland, 2015.

24. ISO 4287:2009. Geometrical Product Specifications (GPS)—Surface Texture: Profile Method-Terms, Definitions and Surface Texture Parameters; International Organization for Standardization: Geneva, Switzerland, 2009.

(C) 2020 by the authors. Licensee MDPI, Basel, Switzerland. This article is an open access article distributed under the terms and conditions of the Creative Commons Attribution (CC BY) license (http://creativecommons.org/licenses/by/4.0/). 